(C) 2014. This manuscript version is made available under the CC-BY-NC-ND 4.0

license http://creativecommons.org/licenses/by-nc-nd/4.0/

\title{
ZERO-POWER-CONSUMPTION THERMOELECTRIC SYSTEM TO PREVENT \\ OVERHEATING IN SOLAR COLLECTORS
}

Alvaro Martinez, David Astrain, Antonio Rodriguez

Department of Mechanical, Energy and Materials Engineering

Public University of Navarra

Campus Arrosadia, Pamplona, 31006, Spain

Tel: +34 948 169309, Fax: +34948 169099, e-mail: alvaro.martinez@unavarra.es

\begin{abstract}
Highly promoted by the European Union Climate and Energy Package for 2020, solar collectors stand out as the most promising alternative to meet water heating demands. One of the most limiting problems in these systems involves the overheating of the working fluid, resulting in rapid fluid degradation, scaling and premature component failure.

This paper presents the computational design of a zero-power-consumption system that combines thermoelectric-self-cooling technology and thermosyphon effect to dissipate the excess heat from a real solar-collector installation. Thermoelectric self-cooling is a novel thermoelectric application proven to enhance the heat dissipation of any hot spot without electricity consumption.

The simplest design outperforms currently-used static and dynamic dissipaters for overheating protection in solar collectors, since it increases the global heat transfer coefficient of a static dissipater by $75 \%$ and requires no electricity. Likewise, the final design presents a global heat transfer coefficient of $15.23 \mathrm{~W} /\left(\mathrm{m}^{2} \mathrm{~K}\right), 155 \%$ higher than that provided by static dissipaters, forming a reliable, robust and autonomous system that stands out as a promising alternative to prevent the overheating of solar collectors.
\end{abstract}

Keywords: Thermoelectric self-cooling; solar collector; overheating; computational model 


\section{Nomenclature}

A

$A_{\mathrm{p}}$

$a_{1}$

$a_{2}$

C

c

cold

$D_{\mathrm{P}}$

$D_{\text {TSC }}$

$D_{\mathrm{u}}$

E

f

$g$

H

$h_{\mathrm{h}}$

hot

I

Joule

K

k

$L_{\mathrm{P}}$

$L_{\mathrm{TSC}}$

M

N

$n$

$P^{+}$

$P^{-}$

$P_{\mathrm{C}}^{-}$
Area

Aperture area of the solar collector

Main factor for thermal loss of the solar collector

Secondary factor for thermal loss of the solar collector

Thermal capacity

Specific heat of the fluid

Cold side of the thermoelectric pairs

Diameter of the connecting pipes

Diameter of the channels of the TSC

Number of design units

Electromotive force produced by a thermoelectric module

Friction factor

Gravity of earth

Height of the solar collector

Vertical distance between the collectors and the TSC

Convective coefficient in the channels of the TSC

Hot side of the thermoelectric pairs

Solar radiation

Electric current through the thermoelectric modules

Joule effect

Coefficient of minor pressure losses

Thermal conductivity of the fluid

Length of the connecting pipes

Length of the channels of the TSC

Number of pairs in a thermoelectric module

Number of thermoelectric modules installed in the TSC

Number of channels of the TSC

Pressure increase provided by thermosyphon effect

Pressure loss in the closed loop

Pressure loss in the collectors $\mathrm{m}^{2}$

$\mathrm{m}^{2}$

$\mathrm{W} /\left(\mathrm{m}^{2} \mathrm{~K}\right)$

$\mathrm{W} /\left(\mathrm{m}^{2} \mathrm{~K}^{2}\right)$

$\mathrm{J} / \mathrm{K}$

$\mathrm{J}(/ \mathrm{kgK})$

m

m

V

$\mathrm{m} / \mathrm{s}^{2}$

m

m

$\mathrm{W} /\left(\mathrm{m}^{2} \mathrm{~K}\right)$

$\mathrm{W} / \mathrm{m}^{2}$

A

$\mathrm{W} /(\mathrm{mK})$

m

m

$\mathrm{Pa}$

$\mathrm{Pa}$

$\mathrm{Pa}$ 
$\begin{array}{lll}P_{\mathrm{P}}^{-} & \text {Pressure loss in the connecting pipes } & \mathrm{Pa}\end{array}$

$\begin{array}{lll}P_{\mathrm{TSC}}^{-} & \text {Pressure loss in the TSC } & \mathrm{Pa}\end{array}$

Pr Prandtl number

Peltier Peltier effect

$\dot{Q} \quad$ Heat flow rate absorbed by the fluid in the solar collectors W

Re Reynolds number

$\begin{array}{lll}R_{\mathrm{c}} & \text { Thermal resistance of the cold side heat exchanger } & \mathrm{K} / \mathrm{W}\end{array}$

$\begin{array}{lll}R_{\text {dis }} & \text { Thermal resistance of each dissipater } & \text { K/W }\end{array}$

$\begin{array}{lll}R_{\mathrm{h}} & \text { Thermal resistance of the hot side heat exchanger } \quad \mathrm{K} / \mathrm{W}\end{array}$

$R_{\mathrm{o}} \quad$ Electrical resistance of a thermoelectric module $\quad \Omega$

$S \quad$ Cross section of the channels $\mathrm{mm}^{2}$

$\begin{array}{lll}T_{\mathrm{e}} & \text { Environment temperature } & { }^{\circ} \mathrm{C}\end{array}$

$T_{\mathrm{h}} \quad$ Average fluid temperature in the channels of the TSC $\quad{ }^{\circ} \mathrm{C}$

$\begin{array}{lll}T_{\mathrm{i}} & \text { Fluid temperature at the inlet of the solar collectors } & { }^{\circ} \mathrm{C}\end{array}$

$T_{\text {o }} \quad$ Fluid temperature at the outlet of the solar collectors $\quad{ }^{\circ} \mathrm{C}$

$T$ Temperature in the time instant $t+\Delta t \quad{ }^{\circ} \mathrm{C}$

Thomson Thomson effect

$t \quad$ Time $\mathrm{s}$

$\begin{array}{lll}U & \text { Heat transfer coefficient } & \mathrm{W} /\left(\mathrm{m}^{2} \mathrm{~K}\right)\end{array}$

$\dot{V} \quad$ Volumetric flow rate of the fluid $\quad \mathrm{m}^{3} / \mathrm{s}$

z Vertical height coordinate m

$\Delta V \quad$ Electric voltage supplied by four thermoelectric modules to a fan $\quad \mathrm{V}$

$\Delta t \quad$ Time step of the computational model $\mathrm{s}$

$\begin{array}{lll}\alpha & \text { Seebeck coefficient } & \mathrm{V} / \mathrm{K}\end{array}$

$\beta \quad$ Tilt angle of the solar collector $\quad$ o

$\eta \quad$ Thermal efficiency of the solar collector

$\eta_{0} \quad$ Optical efficiency of the solar collector

$v \quad$ Kinematic viscosity of the fluid $\quad \mathrm{m}^{2} / \mathrm{s}$

$\rho \quad$ Density of the fluid $\quad \mathrm{kg} / \mathrm{m}^{3}$

$\begin{array}{lll}\tau & \text { Thomson coefficient } & \mathrm{V} / \mathrm{K}\end{array}$ 


\section{Introduction}

The energy consumption of buildings is one of the main topics addressed by the European Union Climate and Energy Package for 2020. This is no surprise, since figures indicate that this sector accounts for about $40 \%$ of the primary energy consumed in the European Union and creates over $40 \%$ of its carbon dioxide emissions [1]. Deeper into these figures, a quarter of this energy -around $170 \mathrm{Mt}$ of oil equivalent per year- is devoted solely to meet water heating demands [2]. The Energy Package strongly promotes the use of renewable sources in this sector, and solar energy emerges as the most promising alternative, especially in southern countries, where the high levels of solar radiation allow savings of about 70-90\% of total water heating cost [3].

In a solar collector system [4], solar radiation is absorbed and the resulting heat is used to warm fresh water in a tank. The heat is transferred from the collectors to the tank by a fluid (usually a mixture of water and glycol) that circulates by natural convection (passive solar systems) or forced by a pump (active solar systems). These systems are designed to cover almost all the water heating demands of a building in summer, and from 40 to $80 \%$ in winter, providing hot water at around $60^{\circ} \mathrm{C}[3,4]$.

One of the most important problems of these systems is the overheating of the working fluid, which takes place when this fluid surpasses its critical high-limit temperature and starts boiling. Repeated overheating causes glycol to degrade and become acidic, accelerates scaling and causes premature component failure $[4,5]$. The overheating of the working fluid can take place under electric power failures, circulator pump failures and maintenance shut-downs. More often, it occurs under excess solar radiation, especially in summer, when the system collects high amounts of heat but the hot water demand is at its lowest level.

Nowadays, there is a wide variety of methods to provide overheating protection. The optimal system must work under all situations, including those where no electric power from the grid is available. Furthermore, it would seem quite contradictory from an energy efficiency 
point of view that, under overheating conditions, not only the energy harvested by the collectors was wasted, but also additional electric power was required to remove this excess.

In the first place, the most novel methods involve the use of scattering layers, thermotropic layers or substances with temperature-based solubility, to regulate the absorbed heat in order to meet instant hot water demands, without electric power consumption. Still under deep investigation, these technologies are due to cope with overheating problems in the future, as soon as their long-term performance is proven and their cost reduced [5].

In the second place, drain-back systems remove the fluid from the pipes before it surpasses its critical high-limit temperature [4]. In the non-electricity-consuming version, the increasing pressure in the pipes forces the fluid to move to a reservoir tank. Then, under high solar radiation, the collectors heat up quickly and reach their equilibrium temperature (called stagnation temperature). The main problems of these systems are caused, firstly, by the presence of remaining fluid in the pipes that overheats and degrades, and, secondly, by the accelerated ageing of the mechanical components under repeated stagnation conditions.

Finally, many solar collectors include static or dynamic dissipaters to transfer the excess heat to the ambient. In the non-electricity-consuming version, the closed loop composed of the collectors, the static dissipaters and the connecting pipes is isolated, and the thermosyphon effect creates the force required to make the fluid circulate [6]. However, static dissipaters work by natural convection, and this mechanism limits their performance to a great extent, imposing low heat transfer coefficients and high sensibility to environment conditions [7].

A previous paper [8] shows a promising new alternative for heat dissipation, called thermoelectric self-cooling (TSC), which joins the advantages of dynamic and static dissipaters. This application uses thermoelectric generation technology to improve the heat transfer of a passive cooling system, such as a static dissipater, without electricity consumption. In a TSC, several thermoelectric modules are installed between a hot spot and a passive cooling system. These modules transform part of the heat into electricity, which is supplied directly to the cooling system. As a result, the cooling system becomes active and its heat transfer coefficient increases. The use of TSC for overheating protection has been explored in a previous paper [9], 
presenting a dissipation system that increases by more than $50 \%$ the global heat transfer coefficient provided by static dissipaters currently-used in solar collectors, and eliminates the influence of the atmospheric wind and the limitations connected to natural convection. However, this TSC requires that the circulation pump works continuously, which renders it useless under the electric power failures and pump malfunctions.

The present paper proposes the idea of combining TSC technology and thermosyphon effect to provide overheating protection to solar collectors for water heating. The main objective is to develop and a computational design of a reliable and autonomous zero-power-consumption TSC system, intended to dissipate the excess heat in a real solar-collector installation, and assess its performance. To this end, the paper is set as follows: Section 2 describes the real solar-collector installation and defines the overheating conditions; then, section 3 introduces the main components of the TSC and describes its performance; after that, section 4 explains the methodology used to conduct the computational design and introduces the expressions that define the thermosyphon effect and the simulation of the TSC. Finally, the results and corresponding analysis are presented in section 5, whereas section 6 summarizes the main conclusions of the work.

\section{Solar collector installation}

The solar-collector system is installed in a one-family house in the north of Spain. It is composed of two flat-plate collectors Astersa AS $-2.6 \mathrm{M}$, set in parallel, both with $55^{\circ}$ of tilt angle, and a storage tank for a maximum of 260 liters of hot water at $60^{\circ} \mathrm{C}$. The characteristics of this solar collector are presented in Table 1 [10]. The thermal fluid is a mixture of water (60 $\%)$ and glycol $(40 \%)$ that circulates under the action of a pump with $40 \mathrm{~W}$ of electric power consumption. Equations (1)-(4) provide respectively the temperature-dependant density, specific heat, thermal conductivity and kinematic viscosity of the fluid [11].

$\rho=1055-0.70 T$ 


$$
\begin{aligned}
& c=3612+3.75 T \\
& k=(350+1.80 T) 10^{-3} \\
& v=(3.02-0.03 T) 10^{-6}
\end{aligned}
$$

The most unfavourable overheating conditions occur when the storage tank is full with water at $60{ }^{\circ} \mathrm{C}$ and there is no demand, so that all the heat harvested by the collectors must be evacuated by the dissipation system. Moreover, the maximum solar radiation in the zone (1000 $\left.\mathrm{W} / \mathrm{m}^{2}\right)$ takes place and combines with the maximum environment temperature $\left(35^{\circ} \mathrm{C}\right)$ and negligible wind speed [12]. To prevent the overheating of the thermal fluid, the system is endowed with two fin-tube static dissipaters, set in parallel and installed after the collectors. Each dissipater presents 6 finned tubes with length $1000 \mathrm{~mm}$ and diameter $16 \mathrm{~mm}$, outer heat transfer area of $4.73 \mathrm{~m}^{2}$ and global heat transfer coefficient (under no-wind conditions) of 5.96 $\mathrm{W} /\left(\mathrm{m}^{2} \mathrm{~K}\right)[13]$. The horizontal area and volume occupied by the two dissipaters reaches $0.48 \mathrm{~m}^{2}$ and $0.019 \mathrm{~m}^{3}$ respectively. When the fluid leaving the collectors reaches $90{ }^{\circ} \mathrm{C}$, it is diverted from the original circuit and forced to flow though the dissipaters, losing the heat previously absorbed. Then, it returns to the original circuit, crosses the tank and goes back to the collectors. The circulation pump must work continuously during all this process.

\section{Thermoelectric self-cooling system}

Figure 1 presents the proposed TSC for overheating protection, which comprises standard thermoelectric modules Kryotherm TGM-287-1.0-1.5 [14] connected electrically in series and thermally in parallel, that harvest heat from the fluid and transform it into electricity. The hot side heat exchanger (HSHE) connects the fluid and the hot side of the modules, and is composed of several aluminium plates with circular channels. Finally, the cold side heat exchanger (CSHE) transfers heat from the cold side of the modules to the environment, comprising several finned dissipaters and axial fans energized by the modules. 
When the fluid temperature at the outlet of the collectors reaches $90{ }^{\circ} \mathrm{C}$, it is forced to flow through the channels of the HSHE. This heat exchanger warms up, inducing a temperature difference between the ends of the thermoelectric modules. Then, the modules provide electric power to the fans, forcing air to flow over the dissipaters. As a result, the thermal resistance between the fluid and the environment decreases, enhancing the global heat transfer coefficient. The fluid cools down as it crosses the TSC and returns to the collectors.

\section{Methodology}

\subsection{Thermosyphon effect}

As can be seen in Fig. 2, once the fluid is enclosed in the dissipation loop, the thermosyphon effect establishes volumetric flow rate that circulates anticlockwise [6]. This volumetric flow rate is such that the pressure increase provided by the thermosyphon effect equals the pressure loss in the collectors, channels of the TSC and connecting pipes, as Eq. (5) indicates. Both terms of Eq. (5) are explained in subsections 4.1.1 and 4.1.2.

$P^{+}(\dot{V})=P^{-}(\dot{V})$

\subsubsection{Pressure increased by thermosyphon effect}

The pressure increase in the fluid is provided by Eq. (6). All the channels of the TSC are horizontal and no temperature gradient has been considered in the connecting pipes.

$$
P^{+}(\dot{V})=\oint(\rho g) \mathrm{d} z=(H \operatorname{sen} \beta+h) \mathrm{g} \rho_{\mathrm{Ti}}-\int_{0}^{H \operatorname{sen} \beta} \rho \mathrm{gd} z-h \mathrm{~g} \rho_{\mathrm{To}}
$$

All the terms are already fixed in previous sections, except the fluid temperature at the collector inlet. Since the outlet temperature is set to $90{ }^{\circ} \mathrm{C}$-which is the highest allowed to 
prevent the overheating- the inlet temperature is calculated with the thermal balance in the collectors, provided by Eq. (7). This inlet temperature and also the final value of the pressure increase are functions of the volumetric flow rate.

$\dot{Q}=\dot{V} \rho c\left(T_{\mathrm{o}}-T_{\mathrm{i}}\right)=A I \eta=A I\left[\eta_{0}-\frac{a_{1}\left(\left(T_{\mathrm{i}}+T_{\mathrm{o}}\right) / 2-T_{\mathrm{e}}\right)}{I}-\frac{a_{2}\left(\left(T_{\mathrm{i}}+T_{\mathrm{o}}\right) / 2-T_{\mathrm{e}}\right)^{2}}{I}\right]$

Equation (6) indicates that $P^{+}$increases as $h$ increases, since the fluid density at the inlet temperature is always higher than that at the outlet temperature, according to Eq. (1), so the vertical distance between the collector outlet and the dissipation system can be increased if needed. However, $h$ higher than zero means that the dissipation system will be under direct solar radiation, reaching high temperatures while being in standby. If so, the first ounces of fluid might boil inside the dissipation system, causing steam hammering and extremely rapid temperature change that can lead to premature ageing and failure. To prevent this, the dissipation system must be installed either behind the collectors, thus reducing $P^{+}$and limiting its applicability to collectors with high tilt angle, or at higher level but covered with a protective layer. It should be noted that the latter would be useless if a static dissipater was used as dissipation system, since the cover would be an obstacle for the air stream created by natural convection, reducing even more the performance of the static dissipater [7]. However, this factor has no significance if a TSC is used, since forced convection is imposed at the outer surface and the air stream is easily oriented.

\subsubsection{Pressure loss in the circuit}

Equation (8) provides the pressure loss in the closed loop, which is composed of that in the collectors, connecting pipes and dissipation system

$$
P^{-}=P_{\mathrm{C}}^{-}+P_{\mathrm{P}}^{-}+P_{\mathrm{TSC}}^{-}
$$


First of all, the pressure loss in a collector is provided by the manufacturer as a function of the volumetric flow rate, and is presented in Table 2.

Secondly, Eq. (9) presents the general expression for the pressure loss in a circular pipe. It is clear that the fluid regime in the connecting pipes must be laminar; otherwise, the pressure loss would be so high that the thermosyphon effect might not suffice to move the fluid. Pipe length is set to $4 \mathrm{~m}$, which seems enough to connect the collectors and the dissipation system, whereas pipe diameter is set to $26 \mathrm{~mm}$ to ensure laminar flow. Then, friction factor can be obtained with Eq. (10) as a function of the Reynolds number, provided by Eq. (11). To conclude, a quite conservative value of 10 is set for the coefficient of minor pressure losses in the pipes, associated with bends, fittings, valves, etc [6].

$$
\begin{aligned}
& P_{\mathrm{P}}^{-}=\left(f \frac{L_{\mathrm{P}}}{D_{\mathrm{P}}}+K\right) \frac{8 \rho}{\pi^{2} D_{\mathrm{P}}^{4}} \dot{V}^{2} \\
& f=64 / \operatorname{Re} \\
& \operatorname{Re}=\frac{4}{\pi D_{\mathrm{P}} v} \dot{V}
\end{aligned}
$$

Finally, the last term in Eq. (8) represents the pressure loss in the channels of the TSC. In the abstract, the volumetric flow rate is different in each channel. However, given that laminar flow must be imposed, this inequality will be insignificant and it will a valid approximation to consider that equal volumetric flow rate circulates through all the channels [6]. Then, Eqs. (9)-(11) are valid to calculate the pressure loss in a single channel, wherein the length and the diameter are design parameters, the volumetric flow rate is the total volumetric flow rate divided by the number of channels, and the coefficient of minor pressure losses are set at 2, comprising two flanged tees [6].

\subsection{Simulation of the TSC}


A computational model, created specifically to simulate TSC applications [15], is used to determine the system performance. Based on the finite differences method, the model is able to simulate the thermoelectric system, including the influence of thermal and electric contacts and all thermoelectric effects (Seebeck, Peltier, Joule and Thomson) with temperaturedependant properties.

The computational model transforms the system into a grid of connected nodes, and solves the non-linear set of equations composed of the thermoelectric effects and the three-dimensional Fourier's law in implicit-finite-differences. Equation (12) provides this expression applied to a node "a" connected to $x$ additional nodes, whereas Eq. (13) provides the thermal resistances between this node and the $x$ additional ones, where $A$ stands for the cross area between nodes and $U$ stands for the corresponding convective, conductive or contact heat transfer coefficient. As can be seen, the model uses the temperatures of all the nodes $(T)$, heat flow $\operatorname{rates}(\dot{Q})$, thermal resistances between nodes $(R)$ and thermal capacities $(C)$ to calculate temperatures in the subsequent time instant $\left(T^{\prime}\right)$

$$
\begin{aligned}
& \frac{1}{R_{\mathrm{a}, 1}}\left(T_{1}^{\prime}-T_{\mathrm{a}}^{\prime}\right)+\ldots+\frac{1}{R_{\mathrm{a}, \mathrm{x}}}\left(T_{\mathrm{x}}^{\prime}-T_{\mathrm{a}}^{\prime}\right)+\dot{Q}_{\mathrm{a}}=\frac{C_{\mathrm{a}}}{\Delta t}\left(T_{\mathrm{a}}^{\prime}-T_{\mathrm{a}}\right) \quad i=1, \ldots, x \\
& R_{\mathrm{a}, \mathrm{i}}=1 / U_{\mathrm{a}, \mathrm{i}} A_{\mathrm{a}} \quad i=1, \ldots, x
\end{aligned}
$$

Inside a thermoelectric module, heat is absorbed by Peltier effect at the hot ends of the $M$ pairs, whereas heat is generated at the cold ends. Equations (14) and (15) present these effects. Likewise, Eq. (16) provides the heat generated by Joule and Thomson effects along the semiconductor legs, being $R_{0}$ the electrical resistance of the thermoelectric module and $\tau$ the Thomson coefficient, derived from Seebeck coefficient by using Eq. (17). Finally, Eq. (18) provides the electromotive force produced by a thermoelectric module. 


$$
\begin{aligned}
& \dot{Q}_{\text {Peltier,hot }}=-M J T_{\text {hot }} \alpha_{\text {hot }} \\
& \dot{Q}_{\text {Peltier,cold }}=M J T_{\text {cold }} \alpha_{\text {cold }} \\
& \dot{Q}_{\text {Joule, Thonson }}=J^{2} R_{0}-M \tau J\left(T_{\text {hot }}-T_{\text {cold }}\right) \\
& \tau=T \mathrm{~d} \alpha / \mathrm{d} T \\
& E=M\left(\left(\alpha_{\text {hot }} T_{\text {hot }}-\alpha_{\text {cold }} T_{\text {cold }}\right)-\tau\left(T_{\text {hot }}-T_{\text {cold }}\right)\right)
\end{aligned}
$$

Figure 3 shows the flow chart of the computational model. The inputs are the temperature of the heat source and the environment, the thermal resistances of the heat exchangers and the number and type of thermoelectric modules, selected from a data base that provides the dimensional, electrical and thermal parameters. The model outputs are voltage, electric current and electric power generated by the modules, efficiency of the thermoelectric conversion, temperatures and heat flow rates transferred between components and generated/absorbed by Joule, Thomson and Peltier effects. Reported deviations between experimental and simulated outputs lay between $\pm 12 \%$ [15].

\subsubsection{Heat source and environment}

As section 2 indicates, the ambient temperature is set at $35{ }^{\circ} \mathrm{C}$, whereas the fluid temperature before the TSC is set at $90{ }^{\circ} \mathrm{C}$. Then, Eq. (7) provides the fluid temperature after the TSC and Eq. (19) calculates the average logarithmic temperature [7]. This average logarithmic temperature is used as heat source temperature in the simulations with the computational model.

$T_{\mathrm{h}}=T_{\mathrm{e}}+\frac{T_{\mathrm{i}}-T_{\mathrm{o}}}{\ln \left(\left(T_{\mathrm{i}}-T_{\mathrm{e}}\right) /\left(T_{\mathrm{o}}-T_{\mathrm{e}}\right)\right)}$

\subsubsection{Thermoelectric modules}


Kryotherm TGM-287-1.0-1.5 thermoelectric module comprises 287 pairs of n-doped and p-doped bismuth-telluride legs. Each leg presents base area of $1 \times 1 \mathrm{~mm}^{2}$ and length of 1.5 $\mathrm{mm}$. They are sandwiched between two similar plates, each of them with base area of 40x40 $\mathrm{mm}^{2}$ and length of $1.5 \mathrm{~mm}$, that provide electrical insulation. The number of thermoelectric modules installed in the TSC is a design parameter.

\subsubsection{Thermal resistance of the hot side heat exchanger}

The thermal resistance of the HSHE includes three effects: heat convection between the fluid and the channel wall, heat conduction through the aluminium plates and thermal contact between the plate surface and the modules. Firstly, this last term has been deeply studied and common values in the literature indicate a heat transfer coefficient of about $21,000 \mathrm{~W} /\left(\mathrm{m}^{2} \mathrm{~K}\right)$, corresponding to a thermal resistance of $0.03 \mathrm{~K} / \mathrm{W}$ for a thermoelectric module with $40 \times 40 \mathrm{~mm}^{2}$ of base area [16]. Secondly, the conductive thermal resistance can be dismissed, given the high thermal conductivity of aluminium and the minimal thickness that the plates should have. Finally, Eq. (20) presents Sieder and Tate's expression to calculate the corresponding convective heat transfer coefficient between the laminar-flow fluid and the wall of a short channel [7]. Reynolds and Prandtl numbers are respectively provided by Eqs. (11) and (21). The number of channels and the diameter of a channel are also design parameters. Then, Eq. (22) provides the thermal resistance of the HSHE.

$$
\begin{aligned}
& h_{\mathrm{h}} D_{\mathrm{TSC}} / k=1.86\left[\left(D_{\mathrm{TSC}} /_{L_{\mathrm{TSC}}}\right) \operatorname{RePr}\right]^{1 / 3} \\
& \operatorname{Pr}=v \rho c / k \\
& R_{\mathrm{h}}=0.03 /_{N}+1 / h_{\mathrm{h}}\left(n \pi D_{\mathrm{TSC}} L_{\mathrm{TSC}}\right)
\end{aligned}
$$

\subsubsection{Thermal resistance of the cold side heat exchanger}

The thermal resistance of the CSHE includes the thermal contact between the modules and the dissipaters, the heat conduction through the dissipaters and the heat convection between 
the dissipaters and the environment. This last term is not obvious, since it depends on the air stream forced over the fins, which in turn depends on the electric power supplied by the modules to the fans. Therefore, the thermal resistance of the CSHE must be introduced as a function of this electric power.

The calculation of the mathematical function that relates these two variables requires the use of computational-fluid-dynamics software and experimental procedures [15]. This calculation has been carried out for the assembly composed of four thermoelectric modules Kryotherm TGM-287-1.0-1.5, connected electrically in series and thermally in parallel, attached to an aluminium finned dissipater comprising a square base plate, with side length $150 \mathrm{~mm}$ and height $12 \mathrm{~mm}$, and 23 fins with dimensions $150 \times 25 \times 1.5 \mathrm{~mm}^{3}$. A fan Sunon KDE1208PTS1 is energized by the four modules, providing forced conversion over the dissipater. Equation (23) shows the obtained relation between the thermal resistance of this dissipater and the voltage supplied by the four modules to the fan [15]. Since the CSHE includes several of these assemblies, the thermal resistance of this heat exchanger can be extrapolated with Eq. (24).

$$
\begin{aligned}
& R_{\mathrm{dis}}=1 /\left(-0.0038 \Delta V^{4}+0.1412 \Delta V^{3}-1.9399 \Delta V^{2}+11.805 \Delta V-22.023\right) \\
& R_{\mathrm{c}}=R_{\mathrm{dis}} 4 / N
\end{aligned}
$$

\subsection{General procedure}

The TSC is divided into several design units $\left(D_{\mathrm{u}}\right)$, each one similar to that presented in Fig. 1, composed of two plates with base area of $40 \times 150 \mathrm{~mm}^{2}$, four thermoelectric modules and one dissipater with the corresponding fan at either side of the plates, similar to those described in section 4.2.4. Therefore, each $D_{\mathrm{u}}$ presents two plates with circular channels, eight thermoelectric modules, two dissipaters and two fans. The heat transfer area of a $D_{\mathrm{u}}$ is $0.39 \mathrm{~m}^{2}$, which corresponds to the external surface area of two dissipaters. The TSC is composed of several $D_{\mathrm{u}}$, set in series and parallel. The design parameters and their levels of variation are the following ones: 
Number of channels of the HSHE: 12, 36, 60

Diameter of a channel of the HSHE: 4, 6, 8, $12 \mathrm{~mm}$

Number of $D_{\mathrm{u}}$ set in parallel: $1,2,3,4,5$

The combination of these parameters leads to 60 different designs for the TSC to be studied. However, some of them are not feasible and are not evaluated. For example, there is no enough space for 60 channels with $12 \mathrm{~mm}$ of diameter in a TSC where all the $D_{\mathrm{u}}$ are set in series. Similarly, a TSC with 12 channels should not have more than $2 D_{\mathrm{u}}$ in parallel; otherwise, the channels would be so separated from each other that the heat transfer between the plates and the modules would worsen significantly.

The volumetric flow rate is not a fixed parameter but depends on the design of the TSC. Therefore, for each of the 60 combinations, four different volumetric flow rates are simulated: $2.22 ; 2.78 ; 4.44$ and $6.66\left(\times 10^{-5} \mathrm{~m}^{3} / \mathrm{s}\right)$. For each case, the computational model provides the number of $D_{\mathrm{u}}$ needed to evacuate the heat absorbed by the fluid in the solar collectors. Then, the real volumetric flow rate will be the one that meets Eq. (5). Finally, Eq. (25) provides the global heat transfer coefficient of the TSC.

$U=\frac{\dot{Q}}{0.39 D_{\mathrm{u}}\left(T_{\mathrm{h}}-T_{\mathrm{e}}\right)}$

\section{Results and Analysis}

In order to show the procedure followed to calculate the working volumetric flow rate for each configuration, Fig. 4 presents that for the TSC installed at the top of the collectors $(h=$ 0), comprising 36 channels with diameter $8 \mathrm{~mm}$ and $4 D_{\mathrm{u}}$ in parallel.

If the volumetric flow rate in the closed loop was $2.78 \times 10^{-5} \mathrm{~m}^{3} / \mathrm{s}$, Eq. (7) would indicate that the fluid would absorb $2911 \mathrm{~W}$ in the collectors (with $57.9 \%$ of thermal efficiency) and the 
inlet temperature would be $62.9^{\circ} \mathrm{C}$. Then, according to Eq. (6), the thermosyphon effect would provide a pressure increase of $160 \mathrm{~Pa}$. This point is the second node on the left forming the solid curve in Fig. 4.

Subsequently, Table 2 would provide a pressure loss in the collectors of $80 \mathrm{~Pa}$ (the volumetric flow rate in a single collector would be $1.39 \times 10^{-5} \mathrm{~m}^{3} / \mathrm{s}$, since the installation has two collectors in parallel). Likewise, Eqs. (9)-(11) would indicate that the pressure loss in the connecting pipes would reach $25 \mathrm{~Pa}$, with Reynolds 1774 , friction factor 0.036 and $16 \mathrm{~Pa}$ of minor pressure losses. Then, Eqs. (20)-(24) would provide the thermal resistances of the heat exchangers that the computational model needs to indicate that the TSC should include $16 D_{\text {u }}$ (4 in series, 4 in parallel) to evacuate the cited $2911 \mathrm{~W}$ of heat, and decrease the fluid temperature from 90 to $62.9^{\circ} \mathrm{C}$. Four $D_{\mathrm{u}}$ in series entail $600 \mathrm{~mm}$-long channels, for a Reynolds number of 107 and a pressure loss in the TSC of only $9 \mathrm{~Pa}$, according to Eqs. (9)-(11). Therefore, the pressure loss in the closed loop would reach $114 \mathrm{~Pa}$, which is represented by the second node on the left of the broken curve in Fig. 4. Finally, Eq. (25) would indicate a global heat transfer coefficient of $10.43 \mathrm{~W} /\left(\mathrm{m}^{2} \mathrm{~K}\right)$.

This procedure is repeated for the rest of the cited volumetric flow rates, and the resulting nodes form the curves in Fig. 4. The intersection of these curves sets the working point, which for this configuration turns out to be $3.35 \times 10^{-5} \mathrm{~m}^{3} / \mathrm{s}$ of volumetric flow rate and $130 \mathrm{~Pa}$ of working pressure. All the information regarding the system performance for this configuration at the working point is included in Table 3, along with the simulation results for the rest of the feasible configurations. Those configurations with 12 channels and diameter 4 or $6 \mathrm{~mm}$ are discarded, since the resulting pressure loss was so high that the thermosyphon effect does not provide enough pressure to move the fluid. The same occurs with the configuration of 36 channels and $4 \mathrm{~mm}$ of diameter. Also, it is physically impossible to allocate 60 channels with diameter $12 \mathrm{~mm}$, since the cross area of the channels is higher than that of the HSHE.

\subsection{Basic system design}


As can be seen in Table 3, the performance of the whole system follows logical patterns. Firstly, Fig. 5a indicates that the total pressure loss reduces as the cross section $(S)$ of all the channels of the TSC increases. Under these circumstances, the thermosyphon effect is able to move higher volumetric flow rates. Secondly, as Fig. $5 \mathrm{~b}$ points out, both the efficiency and the heat harvested by a solar collector reduces as the volumetric flow rate increases, since the average temperature in the collector is higher, thus increasing the heat lost to the environment.

It is common for all thermoelectric applications, either generators or refrigerators, to improve their performance when the thermal resistances of the heat exchangers decrease [16, 17]. In this case, as both thermal resistances decrease, fewer $D_{\mathrm{u}}$ are needed to evacuate the heat. Table 3 indicates that the worst configuration requires $20 D_{\mathrm{u}}$, whereas 16 are required in the best one.

Regarding the HSHE, since laminar flow must be imposed in the channels, the convective heat transfer coefficient reaches low and quite similar values in all the cases [7]. The thermal resistance of the HSHE decreases as the number of channels increases, since the total surface area of the channels increases significantly. However, within each value of $n$, the thermal resistance remains quite similar, since the reduction in the convective coefficient is compensated by the increase in the surface area of the channels. This fact indicates that number of channels has much more influence on the thermal resistance of the HSHE than that of the channel diameter, so it must be the main parameter to bear in mind on designing the HSHE for these applications. Figure 6 shows this effect.

Regarding the CSHE, its thermal resistance is highly influenced by the HSHE, since the decrease in the thermal resistance of the HSHE entails the increase in the electric power provided by the modules to the fans, which rotate faster, thus increasing the air stream through the fins and reducing the thermal resistance of each dissipater [8]. However, this effect is hardly distinguishable, since forced convection is properly obtained in all the cases, so the thermal resistance of the CSHE reaches similar values, as Table 3 indicates.

Finally, results report a maximum heat transfer coefficient of $10.50 \mathrm{~W} /\left(\mathrm{m}^{2} \mathrm{~K}\right)$ for the 
TSC comprising 60 channels with $8 \mathrm{~mm}$ of diameter, $75 \%$ higher than that provided by the static dissipaters used for overheating protection $\left(5.96 \mathrm{~W} /\left(\mathrm{m}^{2} \mathrm{~K}\right)\right.$, as section 2 indicates) [13]. This best configuration is composed of $16 D_{\mathrm{u}}, 4$ in series and 4 in parallel, with 128 modules and 8 aluminium plates, each $0.6 \times 0.04 \times 0.01 \mathrm{~mm}^{3}$ in size. The horizontal area occupied reaches $0.36 \mathrm{~m}^{2}, 25 \%$ less than that occupied by the static dissipaters, whereas the volume reaches $0.036 \mathrm{~m}^{2}$, twice as high.

\subsection{System improvement}

Table 3 indicates that the bottleneck of this application is the thermal resistance of the CSHE, which is more than three times as high as that of the HSHE in the best configuration. In this regard, Table 4 shows the system performance for the best configuration of TSC but improved thermal resistance of the CSHE. To conduct this improvement, Eq. (24) is multiplied by decreasing coefficients, in order to reduce the thermal resistance of each dissipater. Since only the CSHE is modified, the heat absorbed, collector efficiency, volumetric flow rate and working pressure remains invariable, whereas the heat transfer coefficient improves so that fewer $D_{\mathrm{u}}$ are needed to evacuate the heat.

It should be noted that the original design of the TSC, presented in Fig. 3, includes a finned dissipater optimized for thermoelectric applications [18], and it hardly exhibits thermal resistances lower than $0.15 \mathrm{~K} / \mathrm{W}$. Therefore, to obtain thermal resistances significantly lower than that, heat pipes must be included. A heat pipe is a fin-tube heat exchanger that exhibits high heat transfer coefficients, since it includes a phase-change fluid inside, leading to a thermal resistance even an order of magnitude lower than that of a finned dissipater similar in size [19]. A heat pipe presents improved thermal resistance when forced convection is applied over the fins, so the concept of TSC can also be applied to this heat exchanger.

However, the last row in Table 4 indicates that it is useless to reduce the thermal resistance of the heat pipe beyond $0.047 \mathrm{~K} / \mathrm{W}$, since the thermal resistance of the HSHE becomes then the bottleneck, and the system performance does not improve. Therefore, a TSC 
composed of $12 D_{\mathrm{u}}$, with 96 thermoelectric modules, and heat pipes instead of finned dissipaters would provide a global heat transfer coefficient of $13.95 \mathrm{~W} /\left(\mathrm{m}^{2} \mathrm{~K}\right), 134 \%$ higher than that provided by the static dissipaters, and $33 \%$ higher than that of the previous design.

Finally, as section 4.1.1 indicates, force convection allows installing the TSC above the solar collector to increase the pressure provided by the thermosyphon effect, being $h$ the vertical distance between them. Table 5 shows the performance of the whole system with heat pipes for the TSC, but increasing values of $h$. Note that $36 \mathrm{~mm}$ is taken now as diameter of the connecting pipes to impose laminar flow inside them, so the pressure loss in the pipes reduces. As the vertical distance between the collectors and the TSC increases, the thermosyphon effect provides higher volumetric flow rates at higher working pressure. It would be represented in Fig. 4 as if the solid curve moves upwards whereas the broken curve remains constant, so that the intersection moves to the right. As the volumetric flow rates increases, Reynolds number and the convective coefficient increases, according to Eqs. (11) and (20), leading to a final increase in the global heat transfer coefficient. However, given that laminar flow is still imposed in the channels of the TSC, this effect has limited impact on the system performance, and, for $h$ higher than 0.5, it becomes so insignificant that no additional DU can be removed.

Therefore, the best design of a TSC to provide overheating protection to the real solar installation of this work would be elevated $0.5 \mathrm{~m}$ over the top of the collectors, and would be composed of $10 D_{\mathrm{u}}$, with 80 thermoelectric modules, and heat pipes, for a global heat transfer coefficient of $15.23 \mathrm{~W} /\left(\mathrm{m}^{2} \mathrm{~K}\right), 155 \%$ higher than that provided by the static dissipaters and $9 \%$ higher than that of the previous design.

\section{Conclusions}

The main conclusion of this paper is that it is feasible to develop a zero-powerconsumption system to protect solar collectors from overheating. The combination of thermoelectric-self-cooling technology and thermosyphon effect provides a device that dissipates the excess heat and requires no electric power, thus being able to work properly under 
the most unfavourable conditions, such as electric power failures, circulator pump failures, maintenance shut-downs, etc.

The simplest design of the thermoelectric-self-cooling system includes 128 thermoelectric modules Kryotherm TGM-287-1.0-1.5, and the corresponding heat exchangers. The hot side heat exchanger is composed of 8 aluminium plates, $0.6 \times 0.04 \times 0.01 \mathrm{~mm}^{3}$ each, including 60 circular channels with $8 \mathrm{~mm}$ of diameter, through which the fluid circulates. The cold side heat exchanger is composed of 32 finned dissipaters, each one comprising a square base plate with side length $150 \mathrm{~mm}$ and height $12 \mathrm{~mm}$, and 23 fins with dimensions 150x25x1.5 $\mathrm{mm}^{3}$. Finally, 32 fans Sunon KDE1208PTS1, energized by the modules, provide forced convection over the dissipaters.

When the fluid temperature at the exit of the collectors reaches $90{ }^{\circ} \mathrm{C}$, the fluid is forced to flow through the closed loop composed of the collectors, the thermoelectric-self-cooling system and the connecting pipes, where the thermosyphon effect creates the force required to make the fluid circulate. The hot fluid in the channels of the hot side heat exchanger induces a temperature difference between the ends of the thermoelectric modules, which provide electric power to the fans. Then, forced convection is obtained over the dissipaters, leading to a heat transfer coefficient of $10.50 \mathrm{~W} /\left(\mathrm{m}^{2} \mathrm{~K}\right)$ without electricity consumption, $75 \%$ higher than that provided by the static dissipaters currently used for overheating protection.

The thermal resistances of the heat exchangers emerge as key parameters in the system performance, so their improvement increases the global heat transfer coefficient. Thus, the inclusion of heat pipes instead of dissipaters in the cold side heat exchanger leads to a heat transfer coefficient of $13.95 \mathrm{~W} /\left(\mathrm{m}^{2} \mathrm{~K}\right), 33 \%$ higher than that of the first design, which allows a $25 \%$ decrease in the number of modules, from 128 to 96 . Finally, the improvement of the thermal resistance of the hot side heat exchanger comes from the increase in the vertical distance between the dissipation system and the top of the collectors, which boosts the thermosyphon effect, allowing higher volumetric flow rates at higher working pressures and, as a consequence, higher convective heat transfer coefficients between the fluid and the channels. This measure entails an additional $9 \%$ increase in the global heat transfer coefficient, reaching 
$15.23 \mathrm{~W} /\left(\mathrm{m}^{2} \mathrm{~K}\right)$, and a $17 \%$ decrease in the number of modules required, from 96 to 80 . Compared to static dissipaters, the global heat transfer coefficient is improved by $155 \%$.

To conclude, the system joins the advantages of dynamic and static dissipaters, since it overcomes the restrictions related to natural convection and consumes no electricity. Also, it presents the robustness and reliability exhibited by all thermoelectric applications, thus standing out as a promising alternative to prevent the overheating of solar collectors.

\section{Acknowledgments}

The authors are indebted both to the Spanish Ministry of Economy and Competitiveness and the European Regional Development Fund for the economic support to this work, included in the DPI2011-24287 research project.

\section{References}

[1] Directive 2010/31/EU of the European Parliament and of the Council of 19 May 2010 on the energy performance of buildings. www.eur-lex.europa.eu/en/index.htm (celex: 32010L0031), Accessed 24/06/2014.

[2] Consumption of energy in EU, Eurostat, www.epp.eurostat.ec.europa.eu/statistics_explained/index.php/Consumption_of_energy, Accessed 24/06/2014.

[3] R. Shukla, K. Sumathy, P. Erickson, J. Gong, Recent advances in the solar water heating systems: A review, Renew. Sust. Energ. Rev. 19 (2013) 173-190.

[4] J.A. Duffie, W.A. Beckman, Solar Engineering of Thermal Processes, third ed., John Wiley and Sons, Hobocken (USA), 2006, pp. 509-547

[5] M. Slaman, R. Griessen, Solar collector overheating protection, Sol. Energy 83 (2009) 982987.

[6] F.M. White, Fluid Mechanics, fifth ed., McGraw-Hill, New York (USA), 2003. 
[7] W.M. Rohsenow, J.P. Harnett, Y. Cho, Handbook of Heat Transfer, third ed., McGraw-Hill, New York (USA), 1998.

[8] A. Martinez, D. Astrain, A. Rodriguez, Experimental and analytical study on thermoelectric self cooling of devices, Energy 36 (2011) 5250-5260.

[9] A. Martinez, D. Astrain, A. Rodriguez, P. Aranguren, Thermoelectric self-cooling system to protect solar collectors from overheating, J. Electron. Mater. 43 (2014) 1480-1486.

[10] Astersa, Solar thermal collectors, www.astersa.net, Accessed 24/06/2014.

[11] Resol, Heat transfer fluid, www.resol.de/Produktdokumente/TYFOCOR-L.daten.pdf, Accessed 24/06/2014.

[12] M.C. Rodríguez-Hidalgo, P.A. Rodríguez, A. Lecuona, G.L. Gutiérrez-Urueta, R. Ventas, Flat plate thermal solar collector efficiency: Transient behavior under working conditions part II: Model application and design contributions, Appl. Therm. Eng. 31 (2011) 2385-2393.

[13] Konetsu, Static dissipaters, www.konetsu.es, Accessed 24/06/2014.

[14] Kryotherm, Thermoelectric modules, www.kryotherm.ru, Accessed 24/06/2014.

[15] A. Martinez, D. Astrain, A. Rodriguez, Dynamic model for simulation of thermoelectric self cooling applications, Energy 55 (2013) 1114-1126.

[16] D. Astrain, J.G. Vian, A. Martinez, A. Rodriguez, Study of the influence of heat exchangers' thermal resistances on a thermoelectric generation system, Energy 35 (2010) 602610.

[17] Q.N. Nguyen, V.P. Kishore, Behavior of thermoelectric generators exposed to transient heat sources, Appl. Therm. Eng. 51 (2013) 1-9.

[18] D. Astrain, J.G. Vian, Study and optimization of the heat dissipater of a thermoelectric refrigerator, J. Enhanc. Heat. Transf. 12 (2005) 159-170.

[19] R.K. Shah, D.P. Sekulic, Fundamentals of Heat Exchanger Design, first ed., John Wiley and Sons, Hoboken (USA), 2003. 


\section{FIGURES}
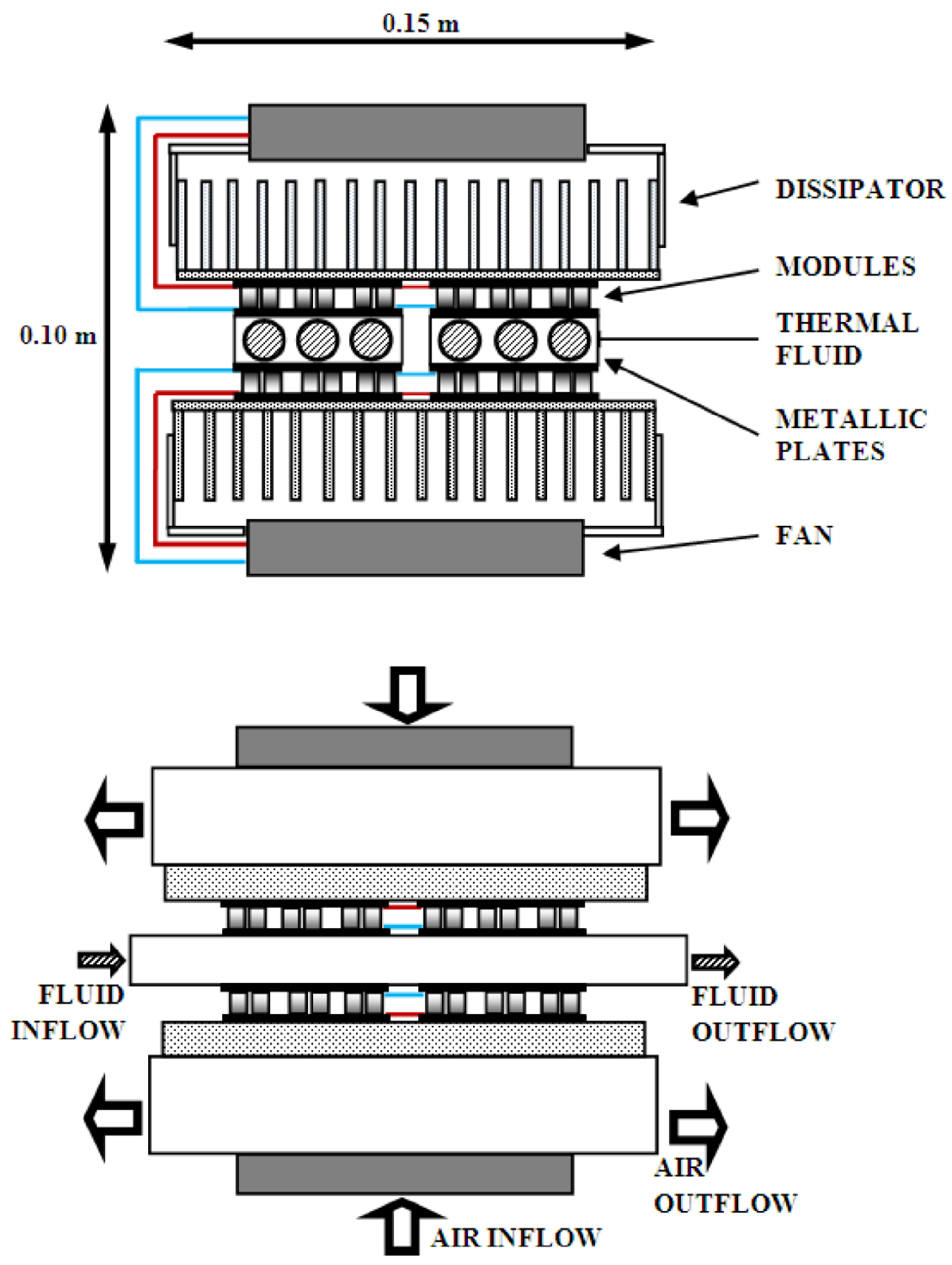

Fig. 1 Front and side view of a design unit of the thermoelectric self-cooling system 


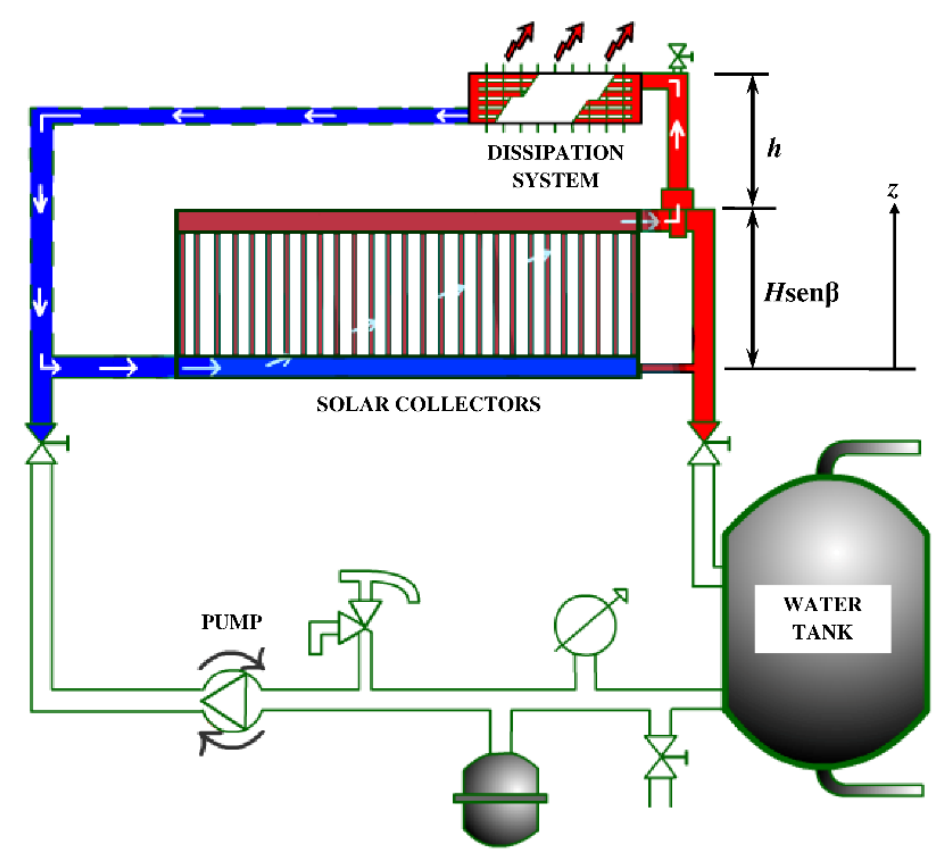

Fig. 2 Diagram of an active solar collector system with thermosyphon closed loop for overheating protection 


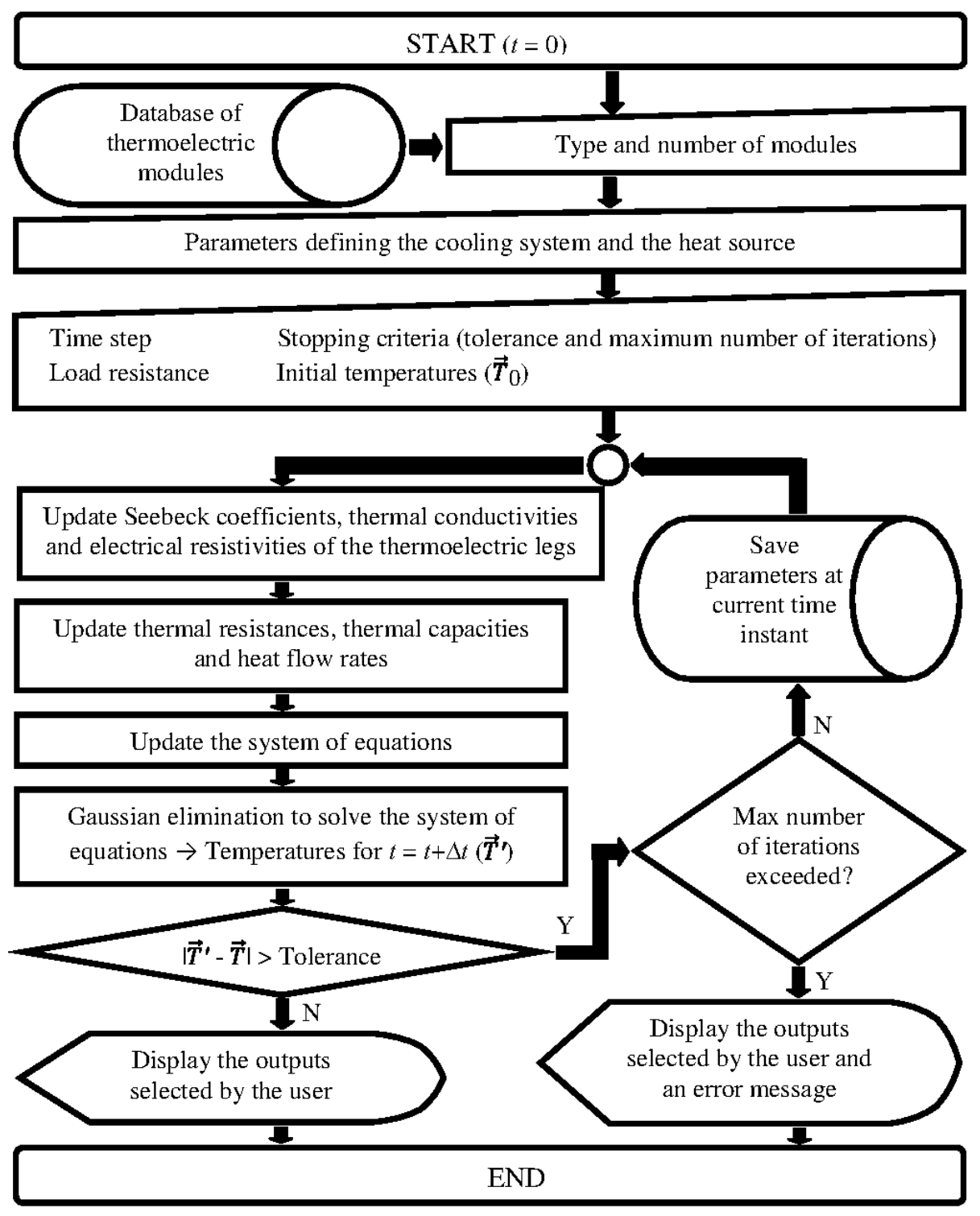

Fig. 3 Flow chart of the computational model 


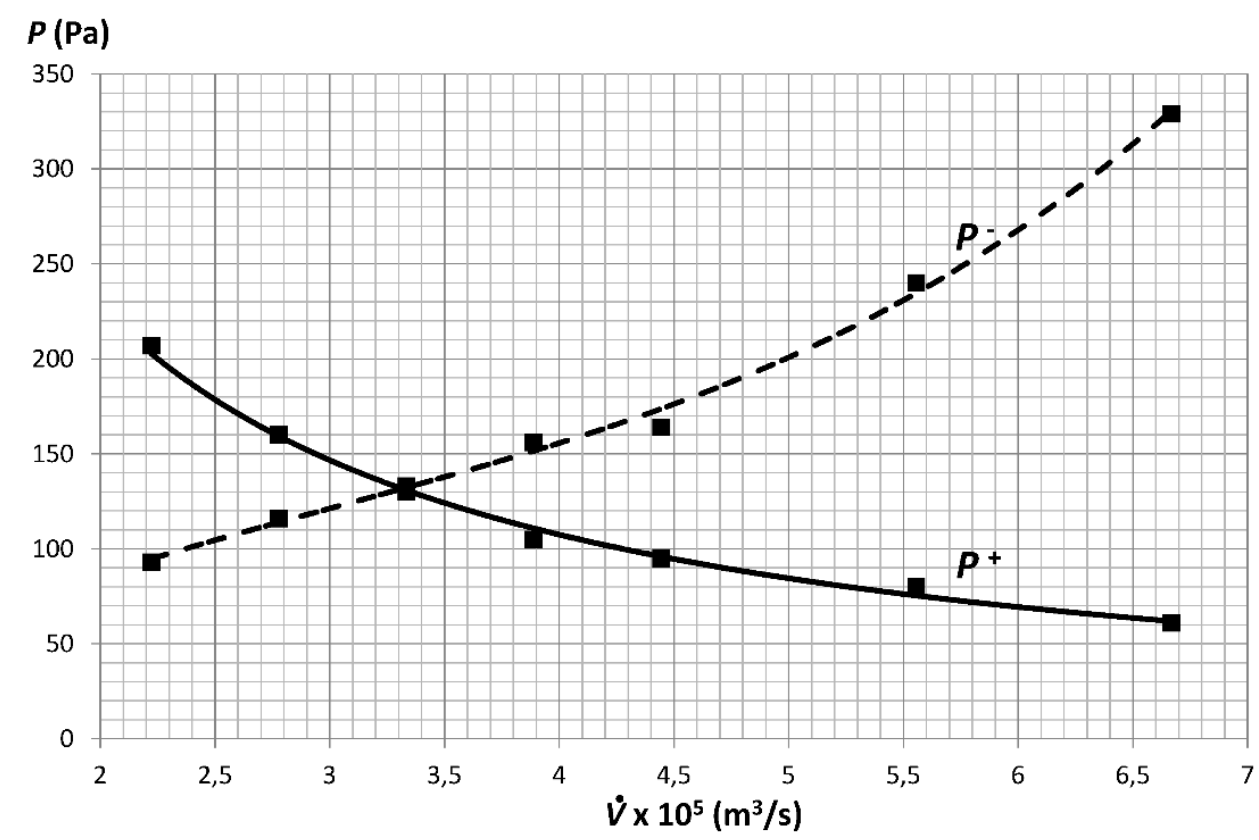

Fig. 4 Working point for the TSC with 36 channels, diameter $8 \mathrm{~mm}$ and $4 D_{\mathrm{u}}$ in parallel
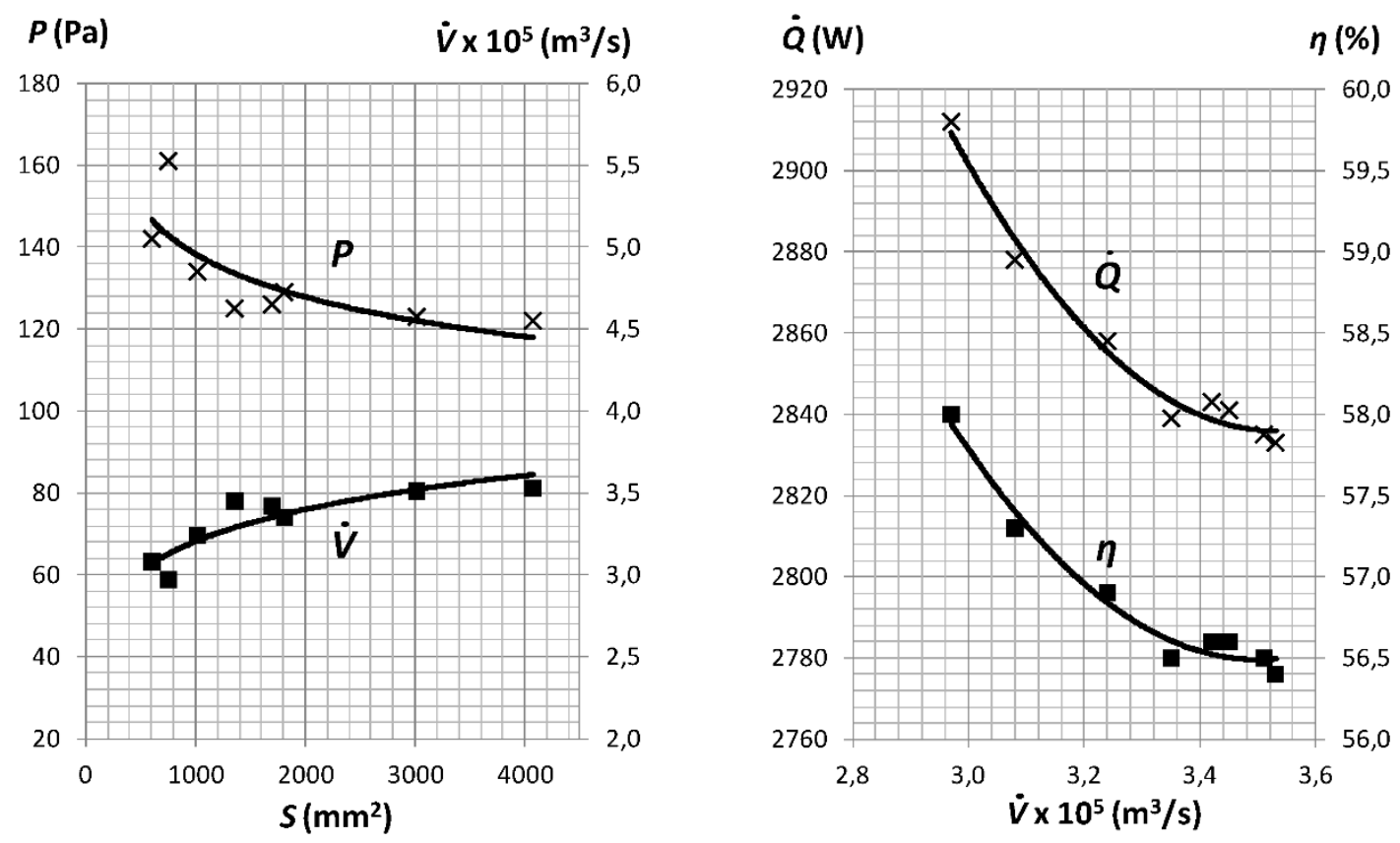

Fig. 5 Performance of the TSC basic design 


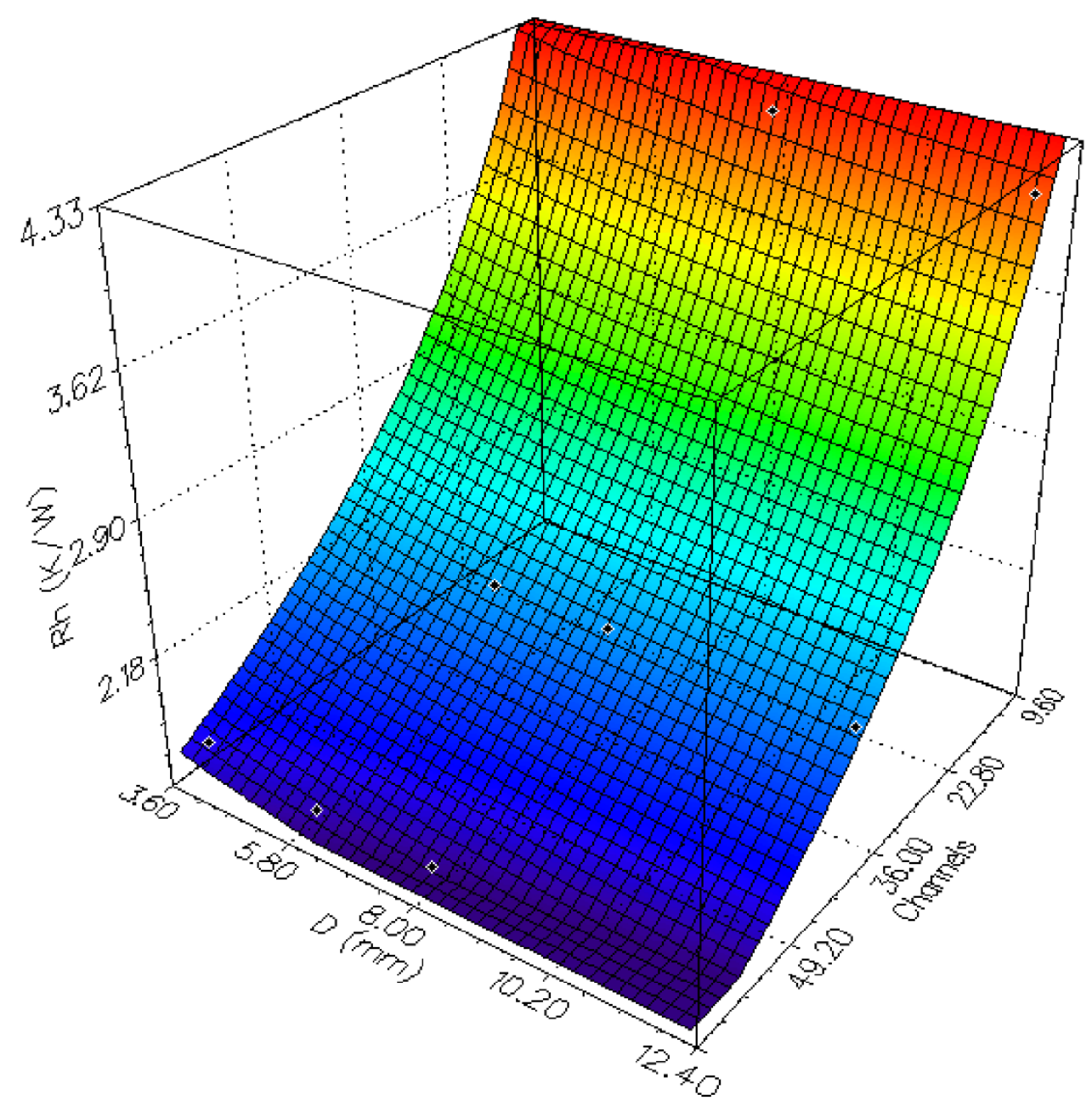

Fig. 6 Influence of the diameter and number of channels on the thermal resistance of the hot side heat exchanger 


\section{TABLES}

\begin{tabular}{|c|c|c|c|}
\hline $\begin{array}{c}\text { Aperture area } \\
2.54 \mathrm{~m}^{2}\end{array}$ & Height & Width & Number of channels \\
& $2.18 \mathrm{~m}$ & $1.259 \mathrm{~m}$ & 10 \\
\hline \multirow{2}{*}{ Optical efficiency } & Main factor for & Secondary factor for & Diameter of the \\
0.748 & thermal loss & thermal loss & channels \\
& $3.44 \mathrm{~W} /\left(\mathrm{m}^{2} \mathrm{~K}\right)$ & $0.015 \mathrm{~W} /\left(\mathrm{m}^{2} \mathrm{~K}^{2}\right)$ & $8 \mathrm{~mm}$ \\
\hline
\end{tabular}

Table 1 Characteristics of the solar collector Astersa AS - 2.6M

\begin{tabular}{|c|c|c|c|c|}
\hline$\dot{V} \times 10^{5}\left(\mathrm{~m}^{3} / \mathrm{s}\right)$ & 1.11 & 1.39 & 2.22 & 3.33 \\
\hline$P_{\mathrm{C}}^{-}(\mathrm{Pa})$ & 65 & 80 & 100 & 200 \\
\hline
\end{tabular}

Table 2 Pressure loss in the solar collector Astersa AS - 2.6M 


\begin{tabular}{|c|c|c|c|c|c|c|c|c|c|c|c|c|c|c|c|c|}
\hline$n$ & $\begin{array}{c}D \\
\mathrm{~mm}\end{array}$ & $\begin{array}{c}\mathrm{S} \\
\mathrm{mm}^{2}\end{array}$ & $\begin{array}{c}\dot{V} \times 10^{5} \\
\mathrm{~m}^{3} / \mathrm{s}\end{array}$ & $\begin{array}{c}\mathrm{Q} \\
\%\end{array}$ & $\begin{array}{c}\eta \\
{ }^{\circ} \mathrm{C}\end{array}$ & $\begin{array}{c}T_{\mathrm{h}} \\
\mathrm{bar}\end{array}$ & $\begin{array}{c}P^{+} \\
\mathrm{bar}\end{array}$ & $\begin{array}{c}P_{\mathrm{C}}^{-} \\
\mathrm{bar}\end{array}$ & $\begin{array}{c}P_{\mathrm{TSC}}^{-} \\
\mathrm{bar}\end{array}$ & $\begin{array}{c}D_{\mathrm{u}} \\
\text { parallel-series }\end{array}$ & $\begin{array}{c}h_{\mathrm{h}} \\
\mathrm{W} /\left(\mathrm{m}^{2} \mathrm{~K}\right)\end{array}$ & $\begin{array}{c}R_{\mathrm{dis}} \\
\mathrm{K} / \mathrm{W}\end{array}$ & $\begin{array}{c}R_{\mathrm{h}} \\
\mathrm{K} / \mathrm{W}\end{array}$ & $\begin{array}{c}R_{\mathrm{c}} \\
\mathrm{K} / \mathrm{W}\end{array}$ & $\begin{array}{c}U \\
\mathrm{~W} /\left(\mathrm{m}^{2} \mathrm{~K}\right)\end{array}$ \\
\hline 12 & 8 & 603 & 3.08 & 2878 & 57.3 & 76.8 & 142 & 75 & 25 & 42 & $2 \times 10$ & 289 & 0.172 & 0.0042 & 0.0043 & 8.82 \\
\hline 36 & 6 & 1018 & 3.24 & 2858 & 56.9 & 77.6 & 134 & 80 & 27 & 27 & $3 \times 6$ & 322 & 0.169 & 0.0021 & 0.0047 & 9.56 \\
\hline 36 & 8 & 1810 & 3.35 & 2839 & 56.5 & 78.6 & 129 & 88 & 31 & 10 & $4 \times 4$ & 284 & 0.166 & 0.0021 & 0.0052 & 10.43 \\
\hline 36 & 12 & 4072 & 3.53 & 2833 & 56.4 & 78.9 & 122 & 89 & 31 & 2 & $4 \times 4$ & 190 & 0.167 & 0.0021 & 0.0052 & 10.34 \\
\hline 60 & 4 & 754 & 2.97 & 2912 & 58.0 & 74.8 & 161 & 65 & 21 & 76 & $3 \times 6$ & 283 & 0.168 & 0.0017 & 0.0047 & 10.43 \\
\hline 60 & 6 & 1696 & 3.42 & 2843 & 56.6 & 78.4 & 126 & 85 & 30 & 11 & $4 \times 4$ & 317 & 0.166 & 0.0016 & 0.0052 & 10.50 \\
\hline 60 & 8 & 3016 & 3.51 & 2835 & 56.5 & 78.8 & 123 & 88 & 31 & 4 & $4 \times 4$ & 240 & 0.166 & 0.0016 & 0.0052 & 10.38 \\
\hline
\end{tabular}

Table 3 System performance for the feasible configurations of the thermoelectric self-cooling system 


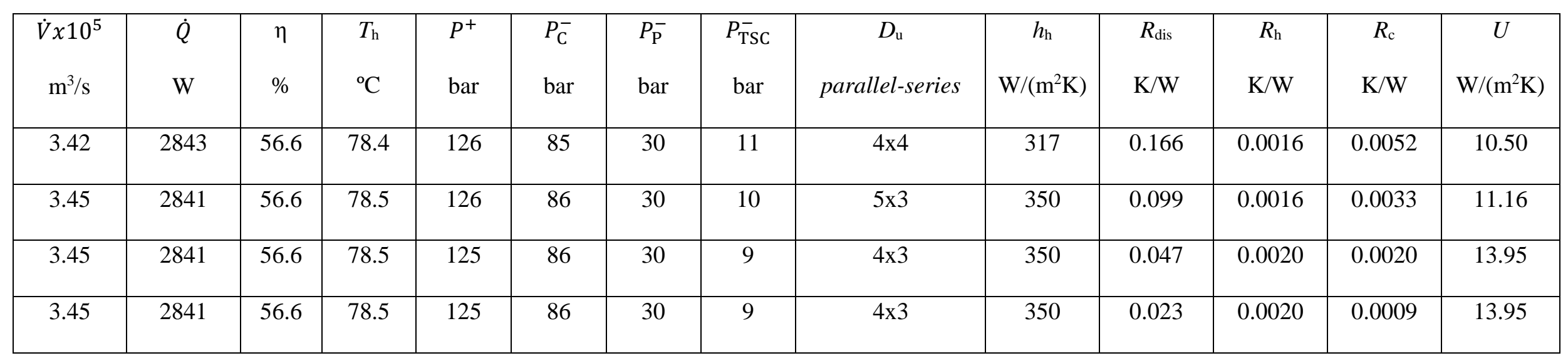

Table 4 System performance for the best configuration of the thermoelectric self-cooling system with improved thermal resistance in the cold side heat exchanger

\begin{tabular}{|c|c|c|c|c|c|c|c|c|c|c|c|c|c|c|}
\hline $\begin{array}{l}h \\
\mathrm{~m}\end{array}$ & $\begin{array}{c}\dot{V} \times 10^{5} \\
\mathrm{~m}^{3} / \mathrm{s}\end{array}$ & $\begin{array}{l}\dot{Q} \\
\mathrm{~W}\end{array}$ & $\begin{array}{l}\eta \\
\%\end{array}$ & $\begin{array}{l}T_{\mathrm{h}} \\
{ }^{\circ} \mathrm{C}\end{array}$ & $\begin{array}{l}P^{+} \\
\text {bar }\end{array}$ & $\begin{array}{l}P_{\mathrm{C}}^{-} \\
\text {bar }\end{array}$ & $\begin{array}{l}P_{\mathrm{P}}^{-} \\
\text {bar }\end{array}$ & $\begin{array}{r}P_{\text {TSC }}^{-} \\
\text {bar }\end{array}$ & $\begin{array}{c}D_{\mathrm{u}} \\
\text { parallel-series }\end{array}$ & $\begin{array}{c}h_{\mathrm{h}} \\
\mathrm{W} /\left(\mathrm{m}^{2} \mathrm{~K}\right)\end{array}$ & $\begin{array}{l}R_{\text {dis }} \\
\text { K/W }\end{array}$ & $\begin{array}{c}R_{\mathrm{h}} \\
\mathrm{K} / \mathrm{W}\end{array}$ & $\begin{array}{c}R_{\mathrm{c}} \\
\mathrm{K} / \mathrm{W}\end{array}$ & $\begin{array}{c}U \\
\mathrm{~W} /\left(\mathrm{m}^{2} \mathrm{~K}\right)\end{array}$ \\
\hline 0 & 3.45 & 2841 & 56.6 & 78.5 & 125 & 86 & 30 & 9 & $4 \times 3$ & 350 & 0.023 & 0.0020 & 0.0009 & 13.95 \\
\hline 0.5 & 4.56 & 2774 & 55.3 & 81.7 & 146 & 125 & 14 & 7 & $5 \times 2$ & 444 & 0.022 & 0.0021 & 0.0011 & 15.23 \\
\hline 1 & 5.18 & 2748 & 54.7 & 82.9 & 174 & 148 & 18 & 8 & $5 \times 2$ & 464 & 0.022 & 0.0020 & 0.0011 & 14.73 \\
\hline
\end{tabular}

Table 5 System performance for the best configuration of the thermoelectric self-cooling system with improved thermal resistance in the cold side heat exchanger and increased thermosyphon effect 